\title{
JEAN PAUL SARTRE Y CLAUDE LÉVI-STRAUSS: notas sobre una polémica en torno al eclesiastés modermo. Epistemología, ciencias humanas y filosofia ${ }^{1}$
}

\author{
Jean Paul Sartre y Claude Lévi-Strauss: notes about \\ a controversy around the modern echlesiastes. \\ Epistemology, human sciences and philosophy
}

\section{Diego A. Mauro}

Prof. y Lic. en Historia. Centro Interdisciplinario de Estudios Sociales (CIESO), Universidad Nacional de Rosario. Becario Doctoral del CONICET. Rosario. Argentina, e-mail: diegoalemauro@hotmail.com

\begin{abstract}
Resumen
El presente trabajo realiza una lectura en clave epistemológica de la polémica animada en la década de 1960 entre Jean Paul Sartre y Claude Lévi-Strauss. Se presentan, a grandes rasgos, la arquitectura del proyecto sartreano en torno a la "preeminencia" de la "razón dialéctica" y la crítica de Lévi-Strauss centrada en las debilidades del "dualismo" razón analítica/razón histórica. Por último, el debate se inscribe en el marco de la problemática relación entre ciencias humanas y filosofía.

Palabras-clave: Estructuralismo; Razón dialéctica; Razón analítica; Epistemología.

\footnotetext{
El presente artículo es una versión reformulada del trabajo de promoción presentado al Doctorado en Humanidades y Artes de la Universidad Nacional de Rosario, en el marco del seminario de posgrado dictado por el prof. José Sazbón durante 2005 en la Facultad de Humanidades y Artes, Rosario, Argentina.
} 


\section{Abstract}

This article carries out an interpretation in epistemological key about the controversy in the 1960 decade between Jean Paul Sartre and Claude Lévi-Strauss. The arquitecture of the Sartrean project around the "preeminence" of the "dialectical reason" and the critic carried out by LéviStrauss, focused in the weaknesses of the "dualism" analitical reason/ historical reason, are presented. At last, the debate is located in the context of the problematical relation between human sciences and philosophy.

Keywords: Estructuralism; Dialectical reason; Analitical reason; Epistemology.

Nada es vanidad; hacia la ciencia y jadelante! exclama el Eclesiastés moderno, es decir, todo el mundo. Y no obstante los cadáveres de los malvados y de los haraganes se tumban sobre el corazón de los otros... ¡Ah! Deprisa, un poco más deprisa: allá abajo, detrás de la noche, esas recompensas futuras, eternas... ¿escaparemos de ellas...?

Arthur Rimbaud El relámpago ${ }^{2}$

A partir de una recuperación del célebre enfrentamiento entre Jean Paul Sastre y Claude Lévi-Strauss, el presente artículo intenta recorrer algunas de las aristas de la epistemológicamente difícil e inestable relación entre ciencias sociales y filosofía.

Transcurridas cuatro décadas, buena parte de aquel debate se presenta en los currículos académicos como caduco, perimido o superado. Sin embargo, a poco de transitarlo se hace evidente que dichos juicios son sólo parcialmente acertados. Detrás de la vertiginosa multiplicación de perspectivas, enfoques y terminologías tanto provenientes de la filosofía como de los magmáticos territorios de las ciencias sociales, es preciso reconocer que muchas de las cuestiones que el debate exhibió crudamente entonces, se encuentran plenamente vigentes y, de hecho, atraviesan los cimientos de las epistemologías contemporáneas.

2 RIMBAUD, Arthur. "El relámpago" en Una temporada en el infierno. Libertador: Buenos Aires, 1998. 
Este trabajo constituye, modestamente, un intento por recuperar, precisamente, la arista epistemológica de aquella polémica, cuyos ejes de interrogación se consideran absolutamente actuales.

En las páginas siguientes se intentará recorrer sucesivamente, en una perspectiva panorámica, el accidentado proyecto sartreano de La Crítica de la Razón Dialéctica para, paso siguiente, desarrollar la crítica levistraussiana de los capítulos finales de El Pensamiento Salvaje. La recuperación de este singular combate, leído en un registro de base, servirá de punto de partida para una reflexión más general sobre las relaciones epistemológicas que, en la coyuntura del debate, entablaron las ciencias sociales y la filosofía. Se preserva al lector la tarea de juzgar, desde su propia perspectiva, la relevancia de los planteos.

\section{La propuesta sartreana}

La Crítica de la Razón de la Dialéctica (CRD), publicada en 1960, es una obra cuanto menos intimidante. Su complejidad, así como la magnitud del proyecto que se proponía enfrentar, han dejado como testimonio una sintaxis desesperada resultado del intento de totalización de dos tradiciones de pensamiento. En El Ser y la Nada, dos décadas antes, Sastre había pensando al hombre como un ser facultado para superar la materialidad en la forma de una libertad trascendente (el pasaje del en-sí al para-sí). Sin embargo esta perspectiva no permitía comprender como tal movimiento podía realizarse en una existencia concreta. La CRD vino, en cierto modo, a intentar saldar dicho déficit.

Después de El Ser y la Nada, Sartre comenzó a preguntarse a la luz de nuevos interrogantes, como conducir un pensamiento nacido de la fenomenología, fundado en la libertad y en el sujeto, más allá de las descripciones existenciales para integrar la totalidad de las relaciones del mundo y de la historia. Sartre creyó encontrar en el marxismo la vía para una respuesta al problema. Sus intentos en esta dirección llenan los voluminosos tomos de la CRD.

En Cuestiones de Método (CM), obra de "circunstancia"3 previa a la CRD, Sartre señalaba que el marxismo degeneraría "en una antropología inhumana" si no reintegraba "al hombre como fundamento suyo" y agregaba

3 Nació de la convocatoria de una revista polaca, en el invierno de 1957, para que Sartre escribiera con el tema "Situación del existencialismo en 1957". El artículo fue después reproducido en Los Tiempos Modernos con ciertas modificaciones. Lo que empezó llamándose Existencialismo y marxismo, terminó convirtiéndose finalmente en Cuestiones de Método. 
que dicha "comprensión", no era otra que "la existencia", que se mostraba "a su vez por el movimiento histórico del marxismo" (SARTRE, 1995, p.139). Era, según Sartre, "la filosofía insuperable", pero se había detenido ("fosilizado", "dogmatizado", "vulgarizado", etc.) y era necesario ponerla nuevamente en marcha dotándola de una categoría de verdad y del soporte existencial, de modo tal de establecer las mediaciones necesarias para una comprensión menos "externa" del hombre. Porque, aclaraba, la "verdadera función de las `ideologías de la existencia' no es describir una abstracta 'realidad humana que nunca ha existido, sino recordar sin cesar a la antropología la dimensión existencial de los procesos estudiados" (SARTRE, 1995, p. 136).

Según Sartre la ideología existencialista no sólo preexistía al saber que vendría a reemplazarla sino que, en un mismo movimiento, lo convocaba. En otras palabras su presencia producía el espacio vacío de un saber que aún no se había consumado y que se presentaba como la vía de reconstrucción del marxismo detenido. "La ideología de la existencia hereda del marxismo, que la ha resucitado, dos exigencias que en él se originan por medio del hegelianismo: si algo así como una Verdad debe poder existir en la antropología, tendrá que llegar a ser, tendrá que hacer su totalización" (SARTRE, 1995, p. 10). Partiendo de esta afirmación axiomática, Sartre concluía que si la relación entre la totalización histórica y la Verdad totalizadora debía existir, siendo esta un doble movimiento del conocimiento y del ser, era justo llamar a este movimiento Razón. "El fin de mi investigación será, pues, establecer si la Razón positiva de las Ciencias naturales es también la que encontramos con el desarrollo de la antropología, o si el conocimiento y la comprensión del hombre por el hombre implica no sólo unos métodos específicos, sino también una nueva razón" (SARTRE, 1995, p. 11), en resumidas cuentas, una razón dialéctica.

Esta última cita de CM señalaba el camino que en breve seguiría Sartre en la CRD y que se recupera aquí atendiendo a los fundamentos y a las derivaciones epistemológicas cuestionadas firmemente desde la antropología por Claude Lévi-Strauss.

La CRD rechazaba la desviación naturalista del marxismo de Engels que conducía a la univocidad de un monismo simplista y proponía la praxis humana como experiencia apodíctica en el mundo concreto de la historia.

[...] Engels le reprocha a Hegel el que imponga a la materia leyes de pensamiento. Pero es precisamente lo que él hace, ya que obliga a las ciencias a verificar una razón dialéctica; al transportarla al mundo "natural", al grabarla en él por la fuerza, Engels le priva de racionalidad, 
ya no se trata de una dialéctica que hace el hombre al hacerse y que además le hace, sino una ley contingente de la que sólo se puede decir: es así y no de otra manera. (SARTRE, 1995, p. 164).

La praxis, dotada de libertad, totalizadora de la experiencia, permitía dar comienzo a la lucha contra el materialismo exterior que desintegraba al hombre en la naturaleza. La CRD intentaba, de este modo, establecer las razones de posibilidad de la razón dialéctica no como inteligibilidad de la historia, ni como ley de desarrollo sino como totalización en acto expresada en la praxis.

Sartre se proponía así demostrar que la dialéctica era tanto el producto de la praxis humana (acción-praxis) como de la "antidialéctica" sufrida. Esta perspectiva ubicaba a las ciencias humanas en el lugar de "disciplinas auxiliares" y las procesaba en un proyecto en el que, tal como lo diría el propio Sartre no podían "encontrar aún su lugar". Un proyecto que se movía, definitivamente, en un registro que relegaba a un plano secundario la dimensión de operatividad que las ciencias humanas reclamaban por entonces como la principal vía de superación de la perspectiva "precientífica" de la filosofía.

La demostración sartreana se basaba en una forma elemental de dualismo entre razón analítica y razón dialéctica. La razón analítica operaba en la naturaleza. Segmentaba, recortaba, dividía, particionaba y, en consecuencia, sólo podía aplicarse a lo estático e inerte. Por el contrario la razón dialéctica era la que operaba en las ciencias humanas aprehendiendo el movimiento, la dinámica por la cual las totalidades negaban la materialidad de las condiciones de existencia (negatividad). El término "dialéctica" señalaba, precisamente, esta impronta de negatividad que constituía el motor de la historia, lo que en terminología de la CRD se denomina "rareza".

Así la Razón analítica, como esquema universal y puro de las leyes naturales, sólo es el resultado de una transformación sintética o, si se prefiere, sólo un determinado momento práctico de la Razón dialéctica: ésta, como los animales-herramientas, utiliza sus poderes orgánicos para -en algunos sectores hacerse residuo casi inorgánico que descifra lo inerte a través de su propia inercia; el pensamiento científico es sintético en cuanto a su movimiento interior (invención de experiencias y de hipótesis) y analítico (si se trata de las ciencias de la Naturaleza en su estado presente) [...] Más lejos veremos -si tiene éxito nuestra experiencia- que la Razón dialéctica sostiene, dirige y vuelve a inventar sin cesar a la Razón positivista como su relación de exterioridad con la exterioridad natural. (SARTRE, 1995, p. 190). 
Se trata de una reelaboración de la "clásica" distinción entre ciencias del espíritu y ciencias de la naturaleza propuesta por Dilthey o en la versión de Windelband entre ciencias nomotéticas y ciencias idiográficas, cuyo correlato metodológico condensaba Droysen en la clásica oposición Erklären-Verstehen.

Si bien la potencia totalizadora de la razón dialéctica era de una calidad diferente como se verá, lo importante aquí era el "rechazo" sartreano de la razón analítica (en una línea cercana a Heidegger) y su ubicación del lado del "acontecimiento", intentando mostrar como podían ser modificadas las estructuras lógicas.

De acuerdo con la CRD la relación entre praxis y materialidad era el principio de una totalización que se manifestaba dialécticamente en la forma de la negación del ser a manos de la praxis que lograba superarse creando nuevas totalidades. Así, la dialéctica no sólo era el proceso de totalización sino, al mismo tiempo, el medio para inteligibilizar el proceso mismo.

La totalización partía siempre de prácticas individuales y al mismo tiempo cada praxis enfrentaba la multiplicidad de totalizaciones; concedida esta posición, la CRD procedía a desarrollar el análisis de las estructuras de estos conjuntos complejos y a describir sus modos de formación y organización. Para, paso siguiente, describir el pasaje de la praxis individual a la praxis proceso (conjunto social) estableciendo un monismo dialéctico fundado en el carácter insuperable de la rareza.

La CRD trataba de aprehender así el concepto "analítico" de estructura, vedette de las ciencias humanas en consolidación y expansión entonces, dentro de la dinámica totalizadora de la dialéctica como el reverso de una relación activa del agente histórico con su grupo. Lo que intentaba demostrar Sastre, detrás de la unidad de los esquemas matemáticos de superficie, era la unidad práctica que los producía y los sostenía en su existencia. En otras palabras se trataba de mostrar que la praxis definía al hombre como acción en el medio de la materia, proponiendo un materialismo que tendría en cuenta el enfrentamiento con el mundo y el "otro" (rareza).

La rareza era según Sartre ontológica. A través de ella intentaba aprehender una suerte de negación absoluta y universal en tanto el hombre, tal como se desarrollaba en la CRD, era el producto de la rareza que introducía la libertad de la praxis en la "frontera ontológica" de la materia (muerte, enfermedad, sistema económico). Constituía con ella una matriz singular que le permitía domesticar el desequilibrio entre el hombre y su entorno. 
De una manera abstracta, se puede tener a la rareza por una relación del individuo con lo circundante. Práctica e históricamente -es decir, en tanto que estamos situados-, lo circundante es un campo práctico ya constituido, que remite a cada uno a estructuras colectivas [...], la más fundamental de las cuales es precisamente la rareza como unidad negativa de la multiplicidad de los hombres. (SARTRE, 1995, p. 260).

La propuesta sartreana, apenas esbozada en estas pocas líneas (que reproducen muy mal las idas y venidas, los giros y los desbarrancos de la argumentación), permiten ver sin embargo, con cierta claridad, como Sartre lograba así (más allá de las dificultades y resistencias lógicas que van emergiendo) integrar los proyectos, en su mirada epistemológicamente parciales, de las diferentes ciencias en la consumación de una antropología racional y totalizadora, cuya piedra angular era la razón dialéctica. Estas observaciones ayudan a problematizar las miradas que, un tanto esquemáticamente, han visto en el enfrentamiento Sartre-Lévi-Strauss, una lucha entre una supuesta "racionalidad filosófica" y otra "científica". El enfrentamiento como se insinúa en la CRD, atravesó transversalmente la cuestión y no respondió, de manera directa, a un alineamiento entre filósofos y científicos sociales.

Por otra parte si bien Sastre ha subrayado firmemente la diferencia de objeto entre las ciencias y la antropología, ha sido menos tajante en lo que se refiere a cuestiones de método. La CRD intentaba traducir una lógica concreta de acción dentro de los cánones formales de un pensamiento demostrativo sin emplear los complejos procesos de verificación, administración y producción de pruebas de las metodologías científicas. Sin embargo, inevitablemente el vacío de saber que la "ideología existencialista" producía y accionaba en el edificio de la CRD, actuaba peligrosamente avanzando sobre el horizonte de las ciencias sociales, no sólo determinando sus potenciales recorridos sino también exigiéndolos. Esta impronta totalizadora de la razón dialéctica, se presentaba como "totalitaria" para las ciencias sociales que difícilmente podían insertarse en un torbellino que se proponía instalar deberes y obligaciones sin espacios de interacción y discusión plurales. Esta era una posibilidad que no admitía el dualismo sarteano.

Indirectamente, la elección del aparato conceptual de la CRD, híbrido entre hegelianismo, marxismo y existencialismo, alejado de la economía explicativa de las ciencias sociales, contribuía a reforzar las dificultades de "síntesis" de la razón dialéctica y fijaba al mismo tiempo una posición al 
respecto. El esfuerza sartreano fue, de todos modos, enorme. La transformación de un pensamiento que se "volvía contra sí mismo" e intentaba trasmutar una filosofía del sujeto en una antropología de la praxis implicaba un trabajo de reelaboración gigantesco. Nociones como las de sujeto, proyecto, comprensión, situación, temporalidad, historicidad e incluso en cierto sentido facticidad se conservan y modifican a la vez. En un intento romántico por salvar lo que en el giro epistémico propuesto debería, tal vez, haber sido abandonado. Sastre hizo todo lo posible por dar a estas nociones pensadas en un contexto subjetivista, una dimensión objetiva, colectiva e histórica.

El proyecto sartreano se debatió en una serie de contradicciones internas que lo dejaron finalmente inconcluso porque la totalización individual no era, más allá de las potentes mediaciones ensayadas, la totalización en la historia. Siguiendo el desenvolvimiento de la CRD se descubren las crecientes dificultades que implicaba cada pasaje de un momento dialéctico a otro. La dialéctica de la praxis individual lograba desembocar en el grupo pero a partir de allí ya no se alcanzaban las instancias mayores como la de los colectivos y las organizaciones sin que la capacidad totalizante se sacrificara frente a la inercia social. Estos problemas a la vez que ponían en evidencia la honestidad del esfuerzo sartreano exhibían crudamente sus límites. Mientras la investigación filosófica de Sartre se estancaba en un punto muerto y el segundo tomo de la CRD recién sería publicado póstumamente, las ciencias humanas se consolidan y expandían tras la adopción de una perspectiva que encontraba el motor de su desarrollo, en la aceptación del descentramiento en relación con el sujeto y que, claramente, rechazaba la axiomática posible de la epistemología insinuada en la CRD.

\section{Algunos tópicos de la polémica}

\section{Las críticas levistraussianas}

Lévi-Strauss había emprendido en El Pensamiento Salvaje (PS), aparecido apenas unos años después del primer tomo de la CRD una verdadera crítica de la "razón histórica" y había establecido su uso legítimo en las fronteras del pensamiento clasificatorio. El choque con Sartre y con una tradición filosófica centrada en la "conciencia histórica" fue desde entonces un hecho sin retorno. El capítulo IX de PS titulado Historia y dialéctica estaba precisamente destinado a refutar la posición sartreana. 
Lévi-Strauss concedía a Sastre que había sabido comprender que el problema de la razón histórica se situaba en la relación entre las estructuras lógicas que determinaban la existencia de los hombres y los acontecimientos que sucedían por fuera de las estructuras; sin embargo cuestionaba la toma de posición sartreana por el acontecimiento. Lévi-Strauss señalaba la evidente contradicción instalada en el seno del dualismo entre razón analítica y razón dialéctica surgido de la aplicación inevitable de la lógica clasificatoria en el núcleo mismo del desarrollo argumentativo de la CRD. Se trataba más bien, como entendía la cuestión Lévi-Strauss, de una razón analítica que desarrollaba su propia crítica refiriéndose a una razón dialéctica que la conducía a sus límites.

Cuando se lee la Crítica, es difícil no sentir que el autor vacila entre dos concepciones de la razón dialéctica. Unas ocasiones, opone razón analítica y razón dialéctica como si opusiera al error y a la verdad [...] otras veces, las dos razones parecen ser complementarias: caminos diferentes que conducen a las mismas verdades. Aparte de que la primera concepción desacredita al saber científico [...] esconde también una curiosa paradoja; pues la obra titulada Crítica de la Razón Dialéctica es resultado del ejercicio que el autor hace de su propia razón analítica: define, distingue, clasifica y opone. (LÉVI-STRAUSS, 1993).

Tal observación cuestionaba los cimientos del edificio filósófico sartreano y suponía además el desmoronamiento del criterio "analítico" de separación de las sociedades salvajes, que Sartre veía en los dominios de la razón analítica en oposición a aquellas dotadas de la capacidad de penetrar el movimiento dialéctico de la historia. Lévi-Strauss por su parte veía en la razón dialéctica los "esfuerzos" llevados a cabo por la razón analítica (torsiones, giros y saltos) en su intento por aprehender la sociedad. Es por ello que según su perspectiva la distinción entre ambas razones no podía ser fundada seriamente. Además, veía detrás de la noción de "conciencia histórica" un esquema abstracto de los hombres, cuya paradoja era la de un "sistema" que invocaba una supuesta historicidad como totalización "ahistórica".

En una mirada panorámica, la crítica levistraussiana concentraba sus energías problematizadoras y críticas sobre tres cuestiones angulares de la CRD: a saber, el legado humanista, la relación de continuidad en el estudio de los fenómenos y la relación entre la historia, el tiempo y la totalización de la conciencia.

Golpeado uno de los centros de base de la CRD, la separación entre razón analítica y razón dialéctica, Lévi-Strauss apunta su crítica 
inmediatamente al soporte humanista que le llegaba a la CRD del famoso escrito de 1945 de Sartre El existencialismo es un humanismo. La posición sartreana cuestionaba la falta de compromiso de la mirada científica que al no reconocer la libertad del hombre, reproducía la figura del esteta, ubicado al costado del camino y descomprometido. Lévi-Strauss reivindica polémicamente la analogía crítica sartreana, invirtiendo su connotación, afirmando: "Aceptamos el calificativo de estetas, por cuanto creemos que el fin último de las ciencias humanas no es constituir al hombre, sino disolverlo" (LÉVI-SATRAUSS, 1993).

El método estructural en antropología rechazaba axiomáticamente las "zonas sartreanas de libertad" porque daba cuenta de determinantes estructurales tras los cuales se alineaban los individuos. El borramiento de la subjetividad que tal distancia epistémica traía consigo posibilitaba reconstruir el plano organizacional de las estructuras. En este sentido se ve como claramente la antropología estructural no podía ser humanista en sentido sartreano.

Basta con reconocer que la historia es un método al cual no corresponde un objeto distinto y, por consiguiente, con recusar la equivalencia entre la noción de historia y la de humanidad, que se nos pretende imponer con el fin inconfesado de hacer, de la historicidad, el último refugio de un humanismo trascendental: como si, a condición tan sólo de renunciar a yoes demasiado desprovistos de consistencia, los hombres pudiesen recuperar, en el plano del nosotros, la ilusión de la libertad. (LÉVI-STRAUSS, 1993).

Este punto de vista era la condición de la recomposición del hombre "disuelto", en otro nivel: el de la riqueza empírica de las formas de humanidad surgidas de la investigación científica, y obturadas en la CRSD por la focalización en torno a la "conciencia histórica". Lévi-Strauss entendía así en contra de Sartre, que la razón analítica no recortaba y particionaba lo real sino que lo aprehendía como conjunto de totalidades (estructuras). En este sentido, el estructuralismo, como programa científico cumplía mejor según Lévi-Strauss, el proyecto del humanismo buscando las regularidades entre los hombres en un nivel epistemológicamente superior al de la conciencia: en el de la diversidad de los comportamientos "externos". La humanidad de este humanismo era una humanidad enunciable sólo al final, como "síntesis parcial" de las reconstrucciones posibles de los procesos científicos de investigación y no el resultado de la especulación apriorística de la filosofía sartreana.

En otras palabras lo que cuestionaba severamente Lévi-Strauss a Sartre era el hecho de que intentara otorgar a la dimensión temporal un prestigio particular "como si la diacronía fundase un tipo de inteligibilidad, no sólo 
superior al que aportaba la sincronía, sino sobre todo de orden más específicamente humano" (LÉVI-STRAUSS, 1993).

Respecto de la cuestión de la continuidad y discontinuidad en el estudio de los fenómenos, las diferencias también eran radicales. En la CRD Sartre partía de la conciencia individual e intentaba integrar en ella el todo de la vida social que se presentaba según la forma del "obstáculo" (en la terminología de la CRD lo "práctico-inerte"). En esta dirección la comprensión de los fenómenos se daba dentro del postulado de la continuidad de la conciencia a todo lo que era perceptible. Las discontinuidades eran así vistas como obstáculos que debían ser superados para restaurar la continuidad original. Siguiendo esta lógica, Sartre reflexionaba que a través de la "seriación" los individuos separados y alienados podían formar una totalidad libre al juntarse con otros. Lévi-Strauss señalaba que esto suponía encerrar la conciencia en su propia sociedad volviendo imposible la percepción de las discontinuidades entre sociedades, porque la conciencia estaba autoseducida por los acontecimientos que movilizaban la sociedad en la que se encontraba anclada, es decir, por esos acontecimientos "históricamente" concebidos como "fundadores" (el ejemplo utilizado era, en clara disputa con Sartre, el de la Revolución Francesa). Se ponía en evidencia así, que la continuidad entre acontecimientos era una función de las preocupaciones contingentes de cada sociedad, que obturaba de esa manera la radical discontinuidad entre los acontecimientos. Según Lévi-Strauss era el historiador quien construía la "historicidad" y producía la historia a partir de sus elecciones.

Hay mucho que decir acerca de esta, pretendida continuidad totalizadora del yo en la que nosotros vemos una ilusión mantenida por las exigencias de la vida social [...] Por consiguiente el hecho histórico no es más dado que los otros; es el historiador, o el agente del devenir histórico, el que lo constituye por abstracción y como si estuviese amenazado de una regresión al infinito. (LÉVI-STRAUSS, 1993).

La crítica levistraussiana desnudaba crudamente el lazo que la "filosofía de la conciencia" había establecido entre la conciencia y la historia humana, para proponer el estudio del hombre en otro terreno: el de la antropología estructural. Se ve así como se proyectaba a partir de la axiomática epistemológica del estructuralismo, una alianza entre ciencias humanas y ciencias naturales, de la cual la filosofía sartreana era excluida.

Por último el problema de la historia y la temporalidad remitía a la estrategia con que Lévi-Strauss se proponía, afirmando su rechazo de la dimensión de la "conciencia histórica", plantear su perspectiva acerca de la 
articulación entre tiempo y estructura. El tiempo, señalaba, no llegaba del exterior a la estructura sino que, más bien, se trataba de la modalidad de funcionamiento de la misma; modalidad que podía ser formalizada fuera del tiempo. En esta dirección concluía que si el tiempo era interior a la estructura, el acontecimiento se presentaba como exterior a la misma, como límite a la lógica clasificatoria.

En esta mirada se ve como la historia no es un "transcurrir" sino interpretación del sentido del acontecimiento en relación a las estructuras que lo preexisten y que deben integrarlo. Así, retomando el cuestionamiento a la mirada sartreana entendía que todas las sociedades estaban en la historia, sólo que utilizaban diferentes sistemas de clasificación para los acontecimientos. Recorría así, a modo de ejemplificación, tres modelos de estructuración del acontecimiento: el del progreso (centrado en la figura de Augusto Comte), el del sacrifico (en la de Robertson Smith) y el del archivo.

Como se ha visto, Lévi-Strauss no comenzaba por una "síntesis subjetiva" para, en un segundo momento, avanzar hacia una "objetiva"; partía de un conocimiento objetivo del mundo del cual el sujeto era un efecto. Concretaba en otras palabras, el pasaje de una filosofía de la historia a una filosofía de la naturaleza. Cuestionaba radicalmente el modelo del progreso comteano porque entendía que la humanidad no pasaba de la magia a la ciencia o del fetichismo al positivismo; sino que, por el contrario, disponía de diversas modalidades de actividad intelectual que eran tanto una como otra, coherentes desde un punto de vista lógico. La filosofía positiva proporcionaba, desde su perspectiva, un modelo de integración de los acontecimientos de acuerdo a una lógica del desarrollo creciente de la ciencia.

Lo mismo afirmaba en relación al modelo del sacrificio que retomaba de la obra clásica de Robertson Smith La religión de los Semitas. En ella el autor planteaba una analogía entre la idea judeo-cristiana según la cual Dios se sacrificaba por los hombres y el principio del totemismo (por el cual no era posible comer el animal totémico sino en banquetes excepcionales). Smith explicaba lo sagrado por una solidaridad entre los hombres y su dios, que era vivida a través de su asesinato y posterior ingesta ritualizada. El modelo proponía un origen absoluto que luego era sujeto a un proceso de descomposición parcial. Lévi-Strauss concluía entonces que el totemismo y el sacrificio no constituían una unidad original sino dos modalidades del pensamiento salvaje. El enfoque levistraussiano veía en el totemismo una homología entre series naturales y culturales, con la capacidad de establecer una discontinuidad entre seres aparentemente continuos; el sacrifico, en sentido contrario, establecía una continuidad entre "seres" o dimensiones que al comienzo se presentaban como 
discontinuos (lo humano y lo divino, la particular y lo universal). El encuentro entre el totemismo y el sacrificio presente en algunas sociedades, constituía un hecho accidental que, según Levi-Strauss, evidenciaba la exploración del pensamiento salvaje en sus dos ejes (naturaleza/cultura -totemismo, y universal/ particular-sacrificio).

En resumidas cuentas lo que Lévi-Strauss intentaba mostrar era que la construcción teórica de Robertson Smith presentaba un modelo posible de integración del acontecimiento en la estructura del pensamiento salvaje. Con estos ejemplos, el autor de Las estructuras elementales del parentesco proponía una crítica de la razón histórica, que evidenciaba las condiciones de posibilidad de "recuperación del tiempo" a la vez en que indirectamente desmontaba el proyecto de la totalización de la razón dialéctica sartreana.

Por último Lévi-Strauss describía el modelo del archivo como la razón de posibilidad de los modelos comteano y smithiano centrados en la producción de un sentido de la historia a partir de un origen. El origen era entendido como el producto del encuentro entre la estructura de la lógica clasificatoria y los problemas reales que constituían su límite. El pensamiento se presenta, de este modo, movilizándose para saturar el horizonte de problemas prácticos que el acontecimiento presenta a la estructura. El modelo del archivo permite al pensamiento clasificatorio la expansión de todas sus posibilidades allí donde el origen las limitaba.

El archivo es, según Levi-Strauss, un dispositivo de conservación de la memoria que posibilita ilimitadas construcciones de relaciones entre datos. Es, en este sentido, una forma de integrar el acontecimiento, sea cual fuere, en la estructura de clasificación, ya que los archivos pueden ser consultados e indagados en función de las problemáticas que el historiador escoja. El modelo del archivo servía a Lévi-Strauss para instalar la historia en la estructura. De este modo podía afirmar que la lógica clasificatoria no se oponía a la historia, si por esta entendemos la interpretación del sentido de los acontecimientos. Se situaría así en los límites de la razón analítica intentando hacer de lo contingente, algo necesario.

El punto de llegada de la argumentación era que los sistemas clasificatorios permitían integrar la historia conclusión que, volviendo al enfrentamiento con Sartre, dejaba a este último situado sobre el acontecimiento, como un efecto de repetición de un origen (en el ejemplo utilizado, la Revolución Francesa) a cuya deconstrucción Lévi-Strauss arremetió breve pero eficazmente. Luego de estos desarrollos desmontaba (más allá de los propios problemas del argumento) la mirada sartreana de la 
historia, proponiendo la dicotomía entre sociedades frías (aquellas que saturarían los acontecimientos en las estructuras preexistentes) y sociedades calientes (aquellas que harían de los acontecimientos ocasiones de relanzamiento del movimiento en la forma de una conciencia histórica).

Lo propio del pensamiento salvaje era precisamente ser intemporal. "Quiere captar el mundo, a la vez, como totalidad sincrónica y diacrónica, y el conocimiento que toma se parece al que ofrecen, de una habitación, espejos fijados a muros opuestos y que se reflejan el uno al otro (así como los objetos colocados en el espacio que los separa), pero sin ser rigurosamente paralelos. Una multitud de imágenes se forman simultáneamente ninguna de las cuales es exactamente igual a las otras; y ninguna de las cuales, por consiguiente, nos aporta más que un parcial de la decoración y del mobiliario, pero cuyo conjunto se caracteriza por propiedades variables que expresan una verdad" (LÉVISTRAUSS,1993). Tal como ilustra la cita, Lévi-Strauss no discutía el hecho de que la razón se transformara en el campo práctico. Lo que pretendía dejar en claro era que, para que dicha transformación pudiera consumarse, es decir para que la praxis pudiera ser vivida como pensamiento, era lógicamente necesario que el pensamiento en sus condiciones iniciales estuviera dado. En resumidas cuentas lo que, en otras palabras afirmaba, era que los conceptos sumergidos en imágenes que Sartre veía como un momento de la dialéctica constituyente, aún dentro de una lógica circular, no le permitían comprender, desde su perspectiva, que toda razón constituyente supone una razón constituida.

El sistema entero del conocimiento humano cobra, así, el carácter de un sistema cerrado. Por tanto, es seguir siendo fiel a la inspiración del pensamiento salvaje el reconocer que el espíritu científico en su forma más moderna, habrá contribuido, en virtud de un encuentro que sólo él supo prever, a legitimar sus principios y a restablecer sus derechos. (LÉVISTRAUSS, 1993).

\section{La respuesta sartreana}

Se ha señalado que Sartre abandonó el campo de batalla antes de las primeras escaramuzas con Lévi-Strauss, y que de hecho no contestó la provocación levistraussina. Sin embargo, tal afirmación merece ser matizada ya que si bien no ofreció un trabajo específico, intervino en diversas oportunidades en el contexto de entrevistas en las que, eventualmente, se le inquiría sobre el asunto. En todo caso sería más atinado señalar que nunca respondió al llamado levistraussiano 
con una obra sistemática, de revisión o reafirmación de sus ideas o de crítica y desmantelamiento del proyecto de una antropología estructural. Sus esfuerzos parecen haber seguido orientados a concluir el proyecto de la CRD, que sin embargo se mostraría irrealizable. Es probable que la agudización de las dificultades metodológicas, teóricas y filosóficas, así como los comentarios adversos dirigidos a la CRD, le decidieran por una cierta cautela (ante la propia percepción de los límites de la axiomática de la CRD) y, en sentido contrario, por un más intenso trabajo político, periodístico y público, en donde podía exhibir, con su propia praxis, los primeros pasos de la CRD. ${ }^{4}$ Sea como fuere en este apartado se analizará, específicamente, una entrevista que Sartre concedió a Bernard Pingaud en 1968 a raíz de una serie de trabajos publicados sobre él, cuando la ruptura entre filosofía y ciencias humanas parecía consolidarse en el contexto de la expansión de los postulados estructuralistas.

En ella comenzaba tomando la reciente obra de Michel Foucault Las Palabras y las cosas, para reafirmar su posición acerca de la praxis. Según Sartre, lo que Foucault presentaba allí era una geología, es decir "la serie de capas sucesivas que forman un 'suelo`. Cada una de las capas define las condiciones de posibilidad de un cierto tipo de pensamiento", pero agregaba que Foucault no decía lo que era "más interesante: es decir, cómo se ha construido cada pensamiento a partir de esas condiciones, ni cómo pasan los hombres de un pensamiento a otro" (SARTRE, 1968, p. 137). Sartre hacía intervenir en este punto a la praxis, única posibilidad de superar lo que entendía era un pseudosmovimiento, la sucesión de una serie de inmovilidades. Así, en su mirada lo que se ponía en jaque tras el estructuralismo, era la teoría de la historia. A las incertidumbres del tiempo se oponía el análisis de las estructuras, único campo de la ciencia. Sartre veía de este modo en el avance del estructuralismo, un modo de desacreditación del paquete epistemológico-político constituido por el marxismo, la historia y la filosofía en nombre de una concepción de ciencia netamente subsidiaria del paradigma positivista-burgués.

No obstante no declaraba la guerra al estructuralismo. Señalaba que no era "en absoluto hostil al estructuralismo cuando el estructuralismo conservaba conciencia de los límites del método" ya que, en su perspectiva, "La estructura no

4 Estas conjeturas tiene una fuente de inspiración en los diálogos y entrevistas que se decidiera a publicar con su compañera Simone De Beauvoir. Ver DE BEAUVOIR, Simone "Conversaciones con Jean Paul Sartre" en DE BEAUVOIR, Simone. La ceremonia del adiós. Editorial Sudamericana: Buenos Aires, 1983; SARTRE, Jean Paul. Autorretrato a los setenta años. Situaciones X, Losada: Buenos Aires, 1970. 
se impone a nosotros más que en la medida en que es hecha por otros" (SARTRE, 1968, p. 138-139). Se reubicaba así en el terreno de la praxis, en la medida en que para comprender como la estructura se estructura era necesario, de acuerdo con la CRD, reintroducir la praxis como proceso totalizador.

El entrevistador avanza sobre la polémica con Lévi-Strauss y le interroga al respecto. Sartre comienza a contestar moderadamente, recordando que Lévi-Strauss ha señalado reiteradas veces su desacuerdo acerca del uso indiscriminado de la perspectiva estructural en terrenos, como el de la crítica literaria, difícilmente domesticables. Pero, paso siguiente, afirma que "tal como Lévi-Strauss lo concebía y lo practicaba, había contribuido en mucho al actual descrédito de la historia, en la medida en que no se aplicaba más que a sistemas ya constituidos". Además, continuaba, "Aun las sociedades más arcaicas, más inmóviles en apariencia, las que Lévi-Strauss llama sociedades "frías", tienen una historia. Esta simplemente tiene un vencimiento más largo que la de las sociedades calientes. En una perspectiva estructural, es decir no dialéctica, es imposible dar cuenta de esa evolución" (SARTRE, 1968, p. 140). Sartre aprovechaba la pregunta para despejar dudas acerca del carácter no histórico de los modos del movimiento "infraestructural", que veía como un fenómeno netamente "pasivo". Porque cuando "ella no muere de muerte heroica, la estructura sucumbe por accidente. Pero nunca son los hombres mismos quienes la modifican, porque no son ellos quienes la hacen: por el contrario son hechos por ella" (SARTRE, 1968, p. 140). Sartre avanzaba en su argumento y lejos de negar la estructura la consideraba un momento de lo práctico-inerte, ya que "la historia no es el orden. Es el desorden. Digamos: un desorden racional. En el mismo momento en que ella mantiene el orden, es decir la estructura, la historia está en vías de deshacerlo". Paso siguiente Sartre se defendía de la acusación de "historicista" señalando que "hay remansos de la historia que son las estructuras. El hombre recibe las estructuras y en este sentido puede decirse que ellas lo hacen. Pero las recibe en tanto él mismo está comprometido en la historia y comprometido de tal modo que no puede dejar de destruirlas" (SARTRE, 1968, p. 141).

Sartre era claro en las respuestas y se aferraba a los pasajes más sólidos de la CRD. Respecto del sujeto veía claramente que aceptar su descentramiento suponía una renuncia a la praxis y con ella al movimiento. De lo que se trataba era de despejar las diferencias entre un sujeto de la praxis y una substancia al modo de la ontología clásica (en la línea en que Heidegger acometiera la tarea). Explicaba Sartre: "Si se insiste en llamar sujeto a una especie de yo sustancial, o una categoría central, siempre más o menos dada, a partir de la cual se desenvolvería la reflexión, entonces hace mucho que el sujeto ha muerto" (SARTRE, 1968, p. 144). 
Como se ve, el desarrollo de la entrevista constituía una respuesta decidida y una reafirmación de los desarrollos de la CRD. Para concluir, Sartre se refería a la relación entre filosofía y ciencia reintroduciendo, precisamente, la diferenciación entre razón analítica y razón dialéctica cuestionada por LeviStrauss. "El método de la ciencia es analítico, el de la filosofía no puede ser más que dialéctico. En tanto interrogación sobre la praxis, la filosofía es al mismo tiempo una interrogación sobre el hombre, es decir sobre el sujeto totalizador de la historia. [...] Lo esencial no es lo que se ha hecho del hombre, sino lo que él hace con lo que se ha hecho de él" (SARTRE, 1968, p. 147). Segmentaba la episteme, como se ve en el párrafo, en dos grandes áreas. La partición era, sin embargo, al mismo tiempo unidad porque, y este era uno de los aspectos más resistidos por Levi-Strauss, ambas tenían una diferente calidad ontológica-cognoscitiva ya que una englobaba a la otra. Lo que se ha hecho del hombre son las estructuras que estudian y describen las ciencias humanas. Lo que el hombre hace es la historia misma, una praxis que, inevitablemente según Sartre, supera las estructuras. Este plano, el de la razón dialéctica contenía y superaba al de la razón analítica en sus diversas formas disciplinares. Es por ello que Sartre se refería a la filosofía como una "bisagra" en condiciones de pensar el conjunto de las totalizaciones parciales que nacían de la praxis. Repetía constantemente que el marxismo era un proyecto a realizar y no un sistema fijado y refiriéndose a los estructuralistas arremetía señalando: "No comprendo entonces que uno se detenga en las estructuras: para mí eso es un escándalo lógico" (SARTRE, 1968, p. 148).

La entrevista de Sartre que se ha recuperado, señala varias cosas. En primer lugar relativiza la idea de que Sartre hubiera abandonado el campo de batalla lisa y llanamente. Se ve en ella, a través de sus respuestas, una destacable claridad lógica y una reafirmación de su pensamiento y del proyecto de la CRD. Apostaba, además, por una claridad expositiva y una sintaxis simplificada que facilitaba la comprensión sistemática de sus ideas y les devolvía la potencia crítica necesaria para polemizar eficientemente. Los rodeos y senderos difíciles impuestos por la CRD, habían contribuido a debilitar su posición frente a la economía del planteo levistraussiano (al menos en sus párrafos de polémica), tal dificultad como se ha apreciado, era evitada acertadamente en las respuestas que le proporcionaba a Bernard Pingaud. En ellas eludía las dificultades del proyecto en el plano de la totalización-Verdad histórica para defender el punto de partida anclado en la praxis y del que dependía epistemológicamente la posibilidad misma del proyecto de la CRD de una filosofía superadora y de síntesis entre existencialismo y marxismo. 


\section{Ciencias humanas y filosofía; estructuras y sujetos}

El presente trabajo ha intentado hasta aquí proporcionar una reconstrucción panorámica de algunas aristas de la polémica entre LéviStrauss y Sartre, atendiendo principalmente el nivel de las diferencias epistemológicas. En este último apartado se intenta proyectar los puntos principales de la discusión sobre el problema más general de la relación entre filosofía y ciencias humanas.

Tal relación adquiría en Sartre, en términos modélicos, la forma de una estructura "vertical" y jerarquizada. En la propuesta de Lévi-Strauss, en sentido contrario, la articulación epistémica se daba en un plano "horizontal". Veamos esto más en detalle. El proyecto sartreano de la CRD, otorgaba a las ciencias humanas el rol de disciplinas auxiliares de la filosofía. Esta circunstancia que para Sartre se presentaba con total naturalidad, y que incluso suponía un reconocimiento estratégico del rol de las emergentes ciencias sociales (toda una concesión de la filosofía), presentaba una organización epistémica jerarquizada que, más allá de la dimensión filosófica, adolecía claramente de una cuota importante de ingenuidad "política". Los crecientes éxitos de las ciencias sociales, nucleadas en torno a la potencia explicativa y científica del método estructural importado por ellas de la lingüística, había consolidado tanto sus identidades profesionales en un plano simbólico como su potencia demandante en términos de reconocimiento social, académico y económico. Su ascendente prestigio y crecientes recursos mal podían aceptar un proyecto filosófico que les planteaba una organización epistémica jerarquizada que, por principio, las incluía subordinadamente. Si como lo veía Sartre, las estructuras constituían un momento de la praxis totalizadora y las ciencias humanas parecían estar encaminadas en el sentido de la identificación y descripción de estas inmovilidades, era lógico que su labor formara parte de un proyecto filosófico envolvente y totalizador que las incorporaba como momentos "auxiliares" de su propio desarrollo.

Sartre dejaba todas las cartas del lado de la filosofía: la organización de los planos epistémicos, la realización de las síntesis, el control de la "verdad" y la consumación del Saber. Las ciencias humanas partícipes del proyecto, eran concebidas como proveedoras de información cuyo procesamiento les estaba vedado en virtud de los límites que la ontología sartreana imponía al método estructural del que se nutrían. Tal modelo vertical, cuya lógica y motor de funcionamiento se aseguraba en la "razón dialéctica" y cuya cima coronaba la labor totalizadora de la filosofía, fue eclipsado por uno alternativo, más acorde 
con los tiempos que corrían, ${ }^{5}$ que en estas páginas se ha visto encarnado en el trabajo de Claude Lévi-Strauss.

La perspectiva levistraussina era claramente diferente y oponía a la verticalización gnoseológica sartreana una horizontalidad basada en la demarcación científica. Desmantelando el proyecto sartreano, Lévi-Strauss veía en la filosofía una práctica especulativa, manifestación de un modo de "conciencia histórica" cuyo universalismo no hacía sino esconder su particularidad y ubicaba a la filosofía más allá de las fronteras de la investigación científica por entonces sujeta al método estructural. Lévi-Strauss ironizaba lúcidamente sobre la CRD señalando que toda su problemática podía condensarse en la interrogación acerca de las condiciones de posibilidad del mito de la Revolución Francesa.

La lógica jerárquica que Sartre proponía detrás de su proyecto de "dialectizar" los conocimientos de las ciencias humanas, era reemplazado por una episteme que excluía a la filosofía e instauraba una horizontalidad de base entre las diferentes ciencias. La negación del principio apodíctico de la CRD, derivaba en una fragmentación de la episteme que encontraba una unidad no "ontológica" sino metodológica en la aplicación de los postulados estructuralistas que permitían (más allá de los matices y de las modos diferenciados de su plasmación operativa) tomar distancia del lastre que la especulación filosófica pretendía imponer a la práctica de las ciencias humanas.

En otras palabras, si la razón dialéctica no era sino un modo de “autoexpansión" de la razón analítica, se ve como la piedra angular en torno a la cual era posible afirmar el modelo vertical sartreano, desaparecía arrastrando el proyecto de síntesis totalizador que traía consigo. Claramente el rechazo de la filosofía en Lévi-Strauss se llevaba a cabo en nombre del saber científico. El lenguaje de la CRD, con su fusión entre marxismo y existencialismo y su confusa y dificultosa sintaxis hegeliana, potenciaba la crítica levistraussiana acerca del carácter especulativo del saber filosófico, que se reducía a "las homofonías y las ambigüedades" que constituían "la materia de esos golpes de teatro especulativos, en cuya ingeniosidad se reconocen los buenos trabajos filosóficos" (LÉVI-STRAUSS, p. 1970, p. 39). Entendía que "el estructuralismo sanamente

5 Para un acercamiento a la coyuntura desde una perspectiva centrada en una historia de la ideas, remitimos a los siguientes trabajos. SAZBON, J. "Razón y método, del estructuralismo al post-estructuralismo". Pensar, epistemología, política y ciencias sociales, Rosario, n. 1, p. 71-103, 2006. SAZBON, José. Sartre en la historia intelectual. Prismas Revista de Historia Intelectual, Buenos Aires, n. 9, p. 10-15, 2005. 
practicado no aportaba un mensaje, no detentaba una llave capaz de abrir todas las cerraduras, no pretendía formular una nueva concepción del mundo, ni siquiera del hombre; se guardaba de querer fundar una terapéutica o una filosofía". ${ }^{6}$ En este párrafo Lévi-Strauss criticaba el carácter totalizador, y por ende no científico de la filosofía, e introducía allí donde Sartre buscaba una Verdad y la totalización de la historia una perspectiva epistémica dominada por un criterio de parcialidad y de exaltación constructiva de los límites del conocimiento. En otras palabras, en el reconocimiento de la fragilidad de todo saber, encontraba Lévi-Strauss la posibilidad de la certeza y de la potencia operativa del discurso científico. Se instauraba, de este modo, una horizontalidad de pares que obviamente dejaba afuera a la filosofía, anclada en la especulación y en el mito romántico de la totalización a partir de la conciencia.

La polémica permite que se manifiesten, con singular claridad, las coordenadas básicas de dos modos de articulación entre ciencias humanas y filosofía. Indirectamente emergen de ella proyectos espistemológicos y políticos opuestos. El autor de Las estructuras elementales del parentesco se presenta sumiendo los intereses prácticos y concretos de unas ciencias humanas ansiosas por transitar la senda estructuralista que las liberaba, precisamente, de la totalización filosófica alentada por Sartre y las acercaba a las ciencias naturales.

En el rechazo levistraussiano de la certeza apodíctica sartreana se aloja el punto de partida del desmantelamiento de la red de asociaciones meramente especulativas que intentaba naturalizar la CRD entre filosofía, praxis, historicidad, sujeto, Verdad totalizadora; y cuyo efecto en términos disciplinares era la implantación de un modo jerarquizado y, en cierto modo, imperialista de integración de las ciencias humanas. ${ }^{7}$

Más allá de la polémica en sí y de sus alcances para nada desdeñables, las ciencias sociales habían decidido ya asumir su mayoría de edad lejos de la filosofía pagando el precio, que luego se mostraría elevado, de aceptar las "imposiciones" del método estructural y de un criterio de demarcación fuertemente restrictivo que corría la tónica de orden del terreno totalizador de la filosofía a la lógica excluyente de las ciencias físico-naturales.

6 "Discours prononcé lors de la réception de la médaille d'or du CNRS" en Le Monde, París, 12 de enero de 1968 [citado en GÓMEZ GARCÍA, Pedro. La filosofía oculta en la antropología estructuralista. Gazeta de Antropología, Granada, n. 2, 1983. Edición digital en internet. Disponível em: <http://www.ugr.es/ pwlac/Welcome1983.html>. Acesso em: 20 dez. 2007.

7 La misma acusación fue lanzada por Sartre en contra del método estructural y su alianza con el discurso científico que sutilmente planteaba la homologación entre ciencia (antropología) y estructuralismo, con efectos peligrosamente imperialistas para el resto de las ciencias humanas. 
La revolución que las ciencias humanas habían comenzado a transitar en nombre de su mayoría de edad presentaba así, más temprano que tarde, los rasgos de un una "revolución traicionada" que las conducía peligrosamente de un modo tutorial a otro no menos asfixiante. Paradójicamente esta había sido una de las líneas de investigación desarrolladas por la CRD.

La revolución "científico-estructural" estaba en marcha y en pocos años, el espíritu libertario y creativo de sus inicios, se mostraría, como indirectamente atestiguan las siguientes palabras de Lévi-Strauss considerablemente ocluido.

Al leer las críticas que ciertos filósofos dirigen al estructuralismo, reprochándole el abolir la persona humana y sus valores consagrados, me siento tan estupefacto como si alguien se sublevara contra la teoría cinética de los gases con el pretexto de que, al explicar por qué el aire caliente se dilata y se eleva, pone en peligro la vida familiar y la moral del hogar, cuyo calor desmitificado perdería así sus resonancias simbólicas y afectivas. (LÉVI-STRAUSS, 1970, p. 570).

\section{Referências}

DE BEAUVOIR, S. Conversaciones con Jean Paul Sartre. En: DE BEAUVOIR, S. La ceremonia del adiós. Buenos Aires: Sudamericana, 1983.

GÓMEZ GARCÍA, Pedro. La filosofía oculta en la antropología estructuralista. Gazeta de Antropología, Granada, n. 2, 1983. Edición digital en internet. Disponível em: <http://www.ugr.es/ pwlac/Welcome1983.html>. Acesso em: 20 dez. 2007.

LEVI-STRAUSS, C. Tristes trópicos. Buenos Aires: EUDEBA, 1970.

Las estructuras elementales del parentesco (I y II). Barcelona: Planeta-Agostini, 1993.

RIMBAUD, A. El relámpago. Una temporada en el infierno. Buenos Aires: Libertador, 1998.

SARTRE, J. P. Jean Paul Sartre contesta. In : PINGAUD, B. (Comp.). Sartre: el último metafísico. Buenos Aires: Paidós, 1968.

$$
1995 .
$$

Crítica de la razón dialéctica (I y II). Buenos Aires: Losada, 
_. Autorretrato a los setenta años. Situaciones X. Buenos Aires: Losada, 1977.

SAZBON, José. Sartre en la historia intelectual. Prismas Revista de Historia Intelectual, Buenos Aires, n. 9, p. 10-15, 2005.

SAZBON, J. "Razón y método, del estructuralismo al post-estructuralismo". Pensar, epistemología, política y ciencias sociales, Rosario, n. 1, p. 71-103, 2006.

Recebido: 11/01/2008

Received: 01/11/2008

Aprovado: $28 / 01 / 2008$

Approved: 01/28/2008 